\title{
The School Reform Under the Background of the New National College Entrance Examination Reform
}

\author{
Hong Qiu1*, Qiaohong Cheng² \\ ${ }^{1}$ Longyan University, Longyan 364012, Fujian Province, China \\ ${ }^{2}$ Normal Education College, Longyan University, Longyan 364012, Fujian Province, China \\ *Corresponding author: Hong Qiu, 2012143018@qq.com
}

\begin{abstract}
Since the promulgation of the new plan for the national college entrance examination reform in 2014, all provinces have been gradually promoting the new college entrance examination reform. In this context, schools are actively carrying out various reforms to improve the quality of education and teaching. However, can school reform only aim at the national college entrance examination? Facing the new national college entrance examination reform, what can schools do?
\end{abstract}

Keywords: New national college entrance examination; School reform

Publication date: November 2021; Online publication: November 30, 2021

\section{Introduction}

For a long time, people believe that the national college entrance examination is the baton of basic education. It determines the "what to teach" and "how to teach" in the stage of basic education. This means that schools would provide courses or teach according to what would be tested in the national college entrance examination. On this basis, the school reform focuses on all aspects of the national college entrance examination. Its purpose is to enable students to achieve high scores in that examination. Therefore, the national college entrance examination has become the decisive factor of the school reform.

The purpose of the national college entrance examination is to select talents for higher education. The examination is implemented because it is fair, objective, and comparable. Other means of selection, such as recommendations, are more subjective. The general purpose of the school reform is to improve the quality of education, promote an all-round development, and cultivate various skills among students. Therefore, it can be seen that the purpose of the school reform is closely related to the two major tasks of school education: enrollment and employment. The national college entrance examination which achieves one of the purposes of school education has become a key factor in the school reform.

However, in the process of school reform, the national college entrance examination should not be the only focus, but the employment of students should also be emphasized. By selecting talents via the national college entrance examination, there will inevitably be students who do not pass the screening. These students would eventually face employment issues. If education only focuses on helping students to pass the national college entrance examination and teaches contents pertaining to the examination, then education in schools would be of no use to them. How then should these students face employment? Therefore, the school reform should take into account both the task of enrollment and employment under the guidance of the general purpose of improving the quality of education and cultivating various skills among students. 
Generally speaking, the purpose of school reform is broader than the national college entrance examination. It does not only include the examination, but also the quality of talent training; it does not only include education and teaching, but also management and culture. However, nowadays, most school reformers take the national college entrance examination as the action guide for the school reform. The setting and arrangement of courses, the methods to evaluate students, as well as the management and evaluation of teachers consider the national college entrance examination as the core. For example, only subjects related to the national college entrance examination are offered, the key subjects of the national college entrance examination are arranged in a relatively concentrated way, students are divided according to test scores, and the enrollment rate is assumed as the critical aspect in teachers' assessment. All these are misunderstandings of the purpose of the school reform and the relationship between schools and the national college entrance examination.

Therefore, only by correctly understanding the relationship between the national college entrance examination and school education, the relationship between the national college entrance examination and the school reform can be better understood. In the process of school reform, it is not only necessary to pay attention to the national college entrance examination and enrollment rate, but also the cultivation of students' literacy and skills, so that students would be able to continue with higher education and meet the challenges of the future society, rather than being geeks or as someone with "high scores but poor in skills."

\section{What can schools do in response to the national college entrance examination?}

If the school reform is aimed only at the national college entrance examination, it would be unscientific. However, the importance of the national college entrance examination to schools is self-evident. It is closely related to both the students and teachers. It directly determines the next step that would be taken by the students as well as the relevant interests of schools and teachers. Therefore, facing the national college entrance examination, what should schools do? In order not to only take into account of the national college entrance examination, but also to improve the quality of education, it is important to cultivate various skills among students and improve their literacy.

\subsection{Changing educational ideas}

Ideas guide behaviors. This means that ideas influence the formation and transformation of an individual's behavioral habits. Therefore, by changing the educational ideas of school reformers and teachers, encouraging them to learn cutting-edge educational theories of the new era, such as "student-oriented," "strengthening moral education and cultivating people," and "quality education," as well as re-establishing and updating their educational ideas, they would be able to fundamentally change their original behavior voluntarily.

In fact, at present, the national college entrance examination is also in the process of reform, where its core value orientation is to guide and promote the all-round development of students ${ }^{[1]}$. Therefore, in the reform process, it is mandatory for schools to establish a proper educational concept of "taking students as the center and promoting the all-round development of students," rather than "taking teachers as the center, scores as the pursuit, and mechanically cultivating students' examination skills." Teachers and school administrators should regard students as a "whole." In the management and teaching process, they should pay attention to the development of students and the cultivation of other skills, create a good environment for the development of students, and promote an all-round development among students.

The change of teachers' educational concept is bound to be directly reflected in their teaching, and the change of their teaching would imperceptibly affect the change of students' concept. This would gradually help students to realize that their focus should not only be on memorizing information mechanically, but 
also to take into consideration of their own needs and desires, build on their own personality and advantages, as well as grow to become masters of their own learning and of themselves rather than just tools for learning. However, the transformation process of educational concept is complex. It is a process of gradual change, which cannot be achieved overnight. In that case, how should school reformers and teachers change their educational ideas? First of all, relevant educational courses should be organized to provide opportunities for them to learn and understand new cutting-edge educational ideas, to reflect and compare with their original ideas, and finally, to allow them to make new choices. Secondly, through the implementation of specific measures of the school reform, allow them to see the changes in schools and in students' learning. This would help them to gradually realize that this phenomenon is different from the original phenomenon and urge them to change their educational ideas through practical results.

In fact, the influence of educational ideas on schools, principals, and even teachers is huge. Educational ideas are revealed consciously or unconsciously. Therefore, the transformation of educational ideas is primary and necessary for them. Establishing new educational concepts, clarifying their responsibilities as educators, and understanding the national college entrance examination from a new perspective are one of the first few things that schools should do to deal in face with the national college entrance examination.

\subsection{Reform the evaluation system}

At present, examination is the main way of evaluation in the field of education in China, and the success or failure of examination is determined by scores. Therefore, this has led to the crazy pursuit of high scores among students, teachers, schools, and other parties. In order to fundamentally change this extreme enthusiasm for scores, the examination should no longer be assumed as the decisive factor for every aspect. Therefore, it is necessary to gradually change this examination-led evaluation method and construct a new evaluation system. The new evaluation system should focus on the all-round development of students to comprehensively reflect students' skills and literacy, rather than simply judging students from one aspect. Schools can evaluate students by considering their participation in school activities, classroom expression, their degree of autonomous learning, and so on. This does not only enable teachers to better understand their students, but also help students to discover their own unique qualities and gain a sense of achievement.

The evaluation system in schools does not only include the evaluation system for students, but also for teachers and the school management. While changing the evaluation system for students, the other two evaluation systems should also be reformed, especially the evaluation system for teachers. In evaluating teachers, the enrollment rate should not be taken as the indicator; in addition, the reward and punishment system for teachers should no longer assume the enrollment rate as the standard. Instead, their teaching skills and quality as well as the relationship between students and teachers should be emphasized, so as to expand the evaluation standard and enrich the evaluation content. In this way, teachers would eventually realize that the evaluation of students cannot be determined only by achievements.

The reform of the evaluation system is not to disregard the evaluation method dominated by examinations, but to reform the standard of this evaluation method so that scores are no longer the determination factor of how well students learn and how well teachers teach. In combination with other evaluation standards and contents, the examination would not only evaluate students' examination skills, but also reflect and evaluate other skills. By all means, it should be supplemented by other evaluation methods, so as to evaluate students more comprehensively.

\subsection{Exploring new teaching methods}

In the past, in order to cope with the national college entrance examination, most schools used simple teaching methods, whereby the students were required to recite or remember the knowledge points related 
to the test contents after being taught. This is a reflection of the traditional teaching method of knowledgecentered and teacher-centered education. However, there is an obvious disadvantage in this teaching method; it neglects the students' learning pattern and suppresses their desire for autonomous learning. This method subdues students as accessories of learning, not masters of their own learning. Therefore, in the process of school reform, it is necessary to change this teaching method and encourage teachers to explore as well as adopt new teaching methods, in order to stimulate students' interest in learning.

In fact, the fundamental purpose of exploring new teaching methods is to create a good interactive link for teachers and students through teaching activities, so that both parties can actively participate. In this way, students' learning is no longer boring and cumbersome, but rather, students would find it easier to learn new information and cultivate relevant skills.

At present, researchers have introduced many new teaching methods, such as the inquiry method, discovery method, non-guiding teaching, etc. The emergence of these new methods poses new challenges to teachers' teaching skills and quality cultivation. Teachers are not only required to impart relevant knowledge, but also to cultivate creative thinking and innovation skills among students through new teaching methods. However, in the actual teaching process, it seems that many teachers do not know how to use these new teaching methods; thus, schools need to provide more time and space for teachers to constantly explore these new teaching methods, in order to determine the ones that suit their own style.

Teaching methods are important in the school reform, but they are one of the most difficult problems faced in the reform. The exploration of teaching methods requires teachers to constantly explore and experiment in teaching activities. This is a long process which requires persistence and change from teachers as well as mutual cooperation and continuous change from students in order to succeed. However, finding a suitable teaching method would help teachers gain twice the results with half the effort, and students would be able develop skills through teaching activities while gaining knowledge.

\subsection{Constructing a diversified and characteristic curriculum system}

School education mainly realizes the dual purpose of educating people and cultivating talents through the curriculum system. Therefore, the reconstruction of the curriculum system is bound to become the core and the main task of the school reform. In order to achieve the training goal of promoting the all-round development of students, the school reform needs to build a diversified and characteristic curriculum system on the basis of the existing curriculum. The construction of a diversified curriculum system is to meet the goals of promoting the all-round development of students and cultivating their skills, while the construction of a characteristic curriculum system is to meet the needs of students' individualized development and cultivate their personalities and talents. On the one hand, this curriculum system would help achieve the goal of educating people and cultivating talents; on the other hand, it would highlight the characteristic development of schools.

At present, most curriculum systems are constructed based on the subjects related to the national college entrance examination; in addition, teaching contents are also selected and organized based on the contents of the national college entrance examination. This phenomenon reflects the single curriculum structure in schools and their lack of characteristics. For example, most courses offered by schools are subject courses, such as Chinese, mathematics, and others. However, the activity curriculum is not well implemented; most courses use the subject system knowledge as the content, emphasize on the systematic teaching of subject knowledge, focus on memorization and mechanical application of knowledge, but neglect students' personalized understanding, construction of knowledge, and the development of their personalities.

Therefore, how should schools construct a diversified and characteristic curriculum system? This can be done by clarifying the structure of the current curriculum system first. Based on this, it is then possible 
to deeply understand how the existing curriculum system is designed and implemented, so as to reconstruct on the basis of the existing curriculum system. Second, by comprehensively analyzing the situation of schools and teachers, such as the school positioning, school running philosophy, school support resources, teacher composition, and teacher expertise, it is then possible to comprehensively explore and gradually construct a characteristic curriculum for each school. Finally, schools can investigate and take into consideration of student resources. Based on the investigation and analysis of students' interests and needs, qualified courses should then be selected from the characteristic courses planned by the schools for key exploration and implementation.

\section{Disclosure statement}

The authors declare that there is no conflict of interest.

\section{References}

[1] Binglin Zhong National College Entrance Examination and Enrollment System Reform and High School Talent Training. Journal of the Chinese Society of Education, (10): 1-5.

[2] Zhang W, 2016, National College Entrance Examination Reform and School Transformation. Educational Science Forum, (04): 1.

[3] Zhong B, 2015, National College Entrance Examination and Enrollment System Reform and High School Talent Training. Journal of The Chinese Society of Education, (10): 1-5.

[4] Qin Y, 2012, What Index Should Be Used to Express Education Quality - Selection and Controversy of Education Quality Index. Research in Educational Development, 32(03): 7-11, 34.

[5] Liu Q, 2003, Research on the Relationship between National College Entrance Examination and School Education. Xiamen University.

[6] Liu P, 2003, Research on School Reform Strategy. East China Normal University.

[7] Han G, Fu Y, Lan D, 2000, Perspective on the Current College Entrance Examination System in China. Journal of Jiangsu University of Technology (Social Science Edition), (03): 54-56, 119. 